\title{
Carpal Antelunar Dislocation and Fenton Syndrome: Extremely Rare Association
}

\section{Mounir Y*, Aharram S, Amghar J, Abdelkrim D and Omar A}

Orthopedic and Trauma Surgery Department A, Mohammed VI-Oujda University Hospital, Morocco

*Corresponding author: Mounir Yahyaoui, Orthopedic and trauma surgery department A, Mohammed VI-Oujda University Hospital, Morocco, Email: mounirdeloin@live.fr

\section{Case Report}

Volume 4 Issue 1

Received Date: March 06, 2020

Published Date: August 18, 2020

DOI: $10.23880 /$ jobd-16000195

\section{Abstract}

Carpal antelunar dislocations are much rarer than posterior dislocations. Their frequencies are between 3 and $6 \%$ of carpal perilunar dislocations. Out of 23 cases of carpal antelunar dislocations listed in the literature, there are only 11 trans-scapho antelunar dislocations.

Carpal antelunar dislocation and Fenton syndrome are two exceptional entities in the literature. In the case of Fenton syndrome, the head of the capitatum is described with a rotation of $90^{\circ}$ to $180^{\circ}$. The association of these two entities remains anecdotal ( 3 cases described).

The anterior approach of carpal antelunar fracture-dislocation was recently honored. This approach offers the benefit of better control of associated intracarpal fractures. In our case, the fracture of the capitatum forced us to a dorsal approach. This approach allowed the reduction and osteosynthesis of the scaphoid satisfactorily. At 3 months, the patient has very good clinical and radiological results.

Keywords: Carpal Antelunar Dislocation; Fenton Syndrome; Rare Association; Surgery

\section{Introduction}

The management of carpal retrolunar dislocation is now well codified, whether it is the preoperative assessment or the surgical technique [1]. The posterior approach is often used in cases of carpal retrolunar dislocation. On the other hand, the management of carpal antelunar dislocations is poorly codified in the literature. The anterior approach is most often recommended [2]. In the case of Fenton syndrome (scaphocapital fracture), the head of the capitate is generally turned 180॰ [3], Boisgard et al. [4], Masmejean, et al. [5]). The authors report a case of antelunar Tran's scapho capital dislocation, with the capitatum head in place. The repair of all the lesions was done through dorsal approach [2].

\section{Clinical Case}

He is a 22-year-old student boy, non-smoking, righthanded, victim 5 months ago of a road accident with reception on his left wrist. The patient was seen late at the consultation after 3 weeks of the trauma. On clinical examination, there was a slightly edematous left wrist, painful mobility, very reduced in flexion-extension, preserved in pronosupination with reduction in grip strength. The patient underwent a standard radiographic assessment (Figure 1) and a wrist CT (Figure 2) showing a fracture dislocation trans sapho antelunar of the carp. The patient was operated by a posterior approach (Figure 3), allowing reduction of dislocation, osteosynthesis of the scaphoid by a Herbert screw, osteosynthesis of the 
capitatum also by a Herbert screw from proximal to distal and putting a luno triquetral pin removed at 6 weeks to begin rehabilitation. Postoperative immobilization was done by an antebrachiopalmary splint for 6 weeks.

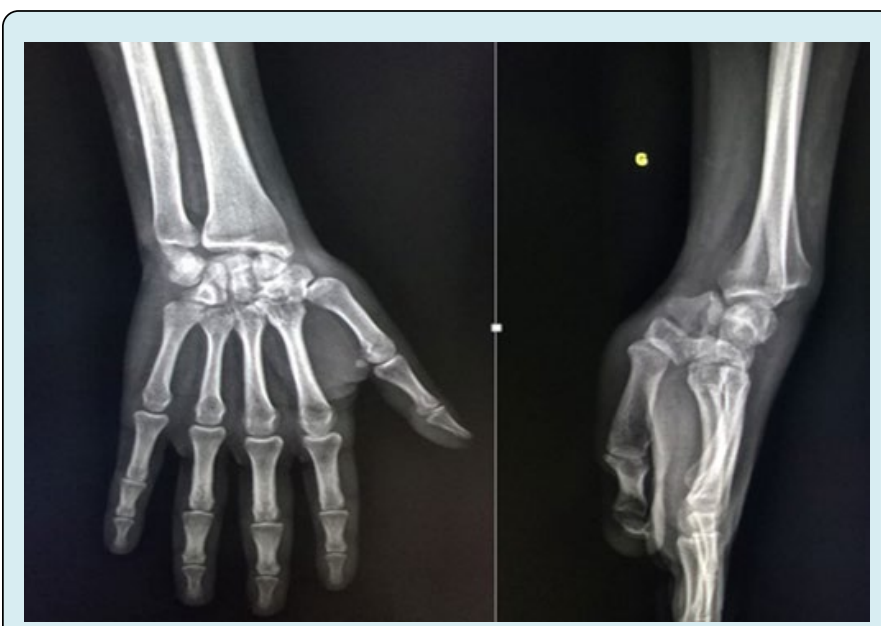

Figure 1: Preoperative radiographs of the left wrist, face and profile.

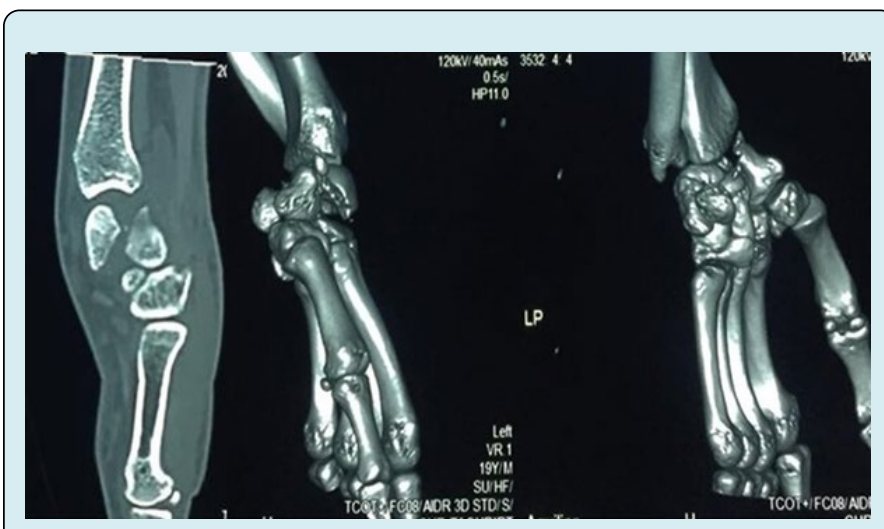

Figure 2: CT aspect of the fracture dislocation antelunar trans scapho capital.

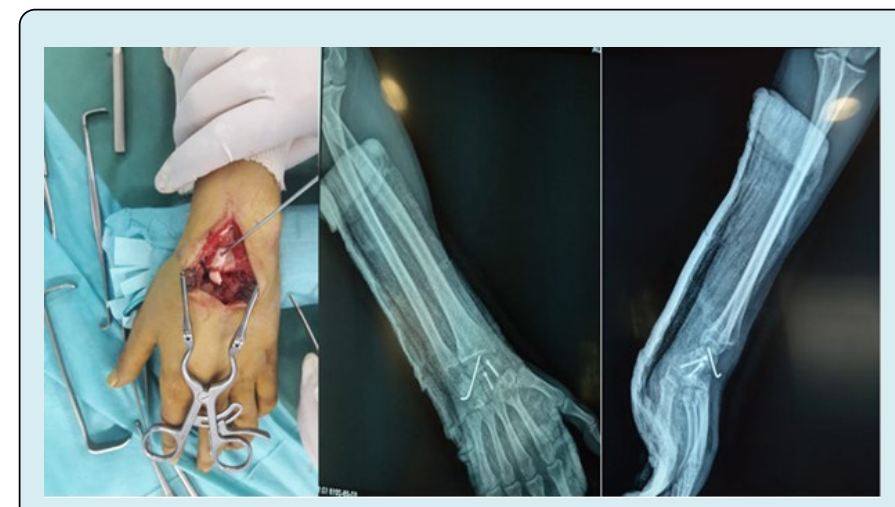

Figure 3: Surgery by dorsal approach / $\mathrm{R}$ * for immediate postoperative control.

\section{Results}

The patient was seen again in consultation, the last one dates back 4 months from the intervention. He presented no handicap in daily life. His left wrist was strictly painless. The wrist mobilities were $60^{\circ}$ in flexion and $80^{\circ}$ in extension (Figure 4). The pronosupination was correct since the trauma. Its grip strength, compared to the healthy side, is almost normal. On the radiological level, there was complete consolidation of the various foci of fracture without intracarpal misalignment that is to say without DISI or VISI and with a scapholunar angle within the limits of normal value (Figure 5).

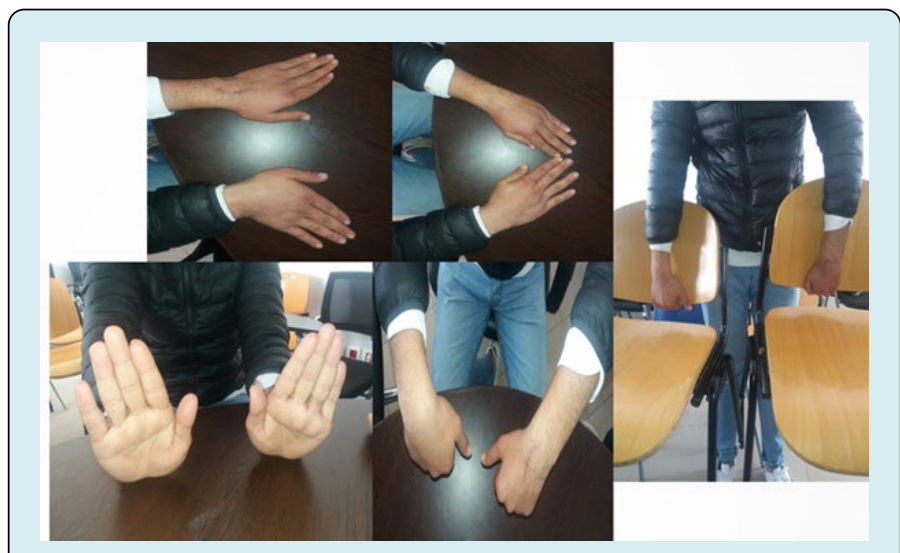

Figure 4: Functional results at 3 months of surgery.

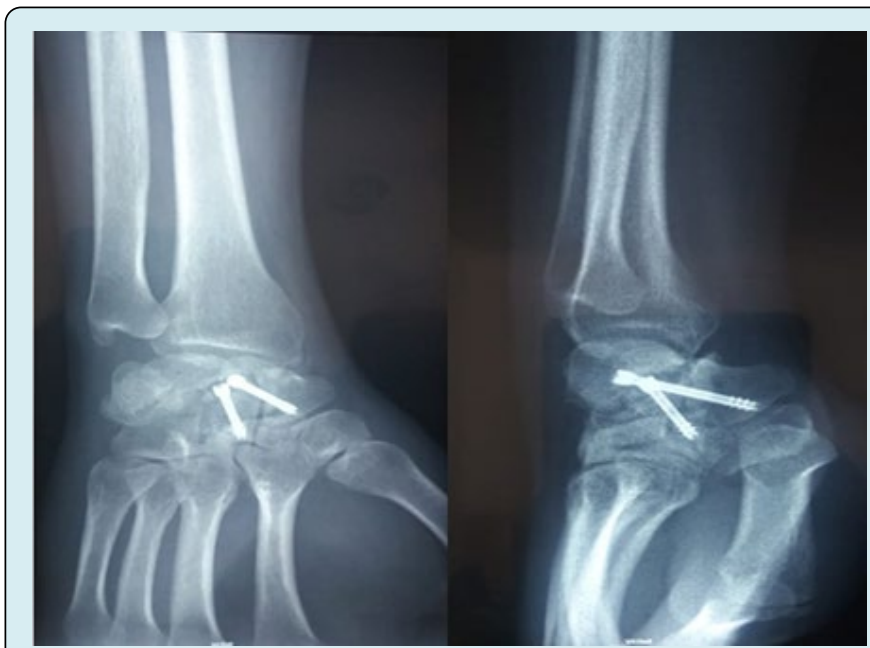

Figure 5: Control radiographs 3 months after surgery.

\section{Discussion}

Carpal antelunar dislocations are much rarer than posterior dislocations. The first case was described by Speed in 1925 [6]. The first observation dealing with the mechanism and the treatment was made by Aitken and 


\section{Journal of Orthopedics \& Bone Disorders}

Nalebuff [6] in 1960. Vichard, et al. [7] reported 4 cases in 20 years of exercise, while 61 retrolunar luxations were observed during the same period. Ourab, et al. [8] have listed 3 carpal antelunar dislocations in 17 years of exercise, while 76 retrolunar dislocations have been identified. All these data place the frequency of antelunar carpal dislocations between 3 and $6 \%$ of carpal perilunar dislocations. Out of 23 cases of carpal antelunar dislocations identified in the literature, there are only 11 Trans scapho antelunar dislocations [8]. Carpal antelunar dislocation occurs in young adult males following violent trauma. This explains the frequent association with polytrauma which risks neglecting dislocation. Their mechanism of occurrence is most often direct impact on the hand back in palmar hyperflexion $[6,9,10]$.

Carpal antelunar dislocation and Fenton syndrome are two exceptional entities in the literature. In the case of Fenton syndrome, the head of the capitatum is described with a rotation of $90^{\circ}$ to $180^{\circ}$. The association of these two entities remains anecdotal (3 cases described) [2]. The authors report a case of antelunar trans scapho capital dislocation, with the capitatum head in place [2].

Since the description by Fenton in 1956 [11], less than 30 cases of scaphocapital fracture have been found in the literature. In a multicenter study of 166 perilunar dislocations, Herzberg found only 4 cases of retrolunar transscapho dislocation associated with a fracture of the capitate head and 5 other cases of antelunar dislocation [1]. Vance et al. were the first to try to understand the lesional mechanism of this entity and to classify this syndrome. There is always a trauma on the head of the capitatum, either directly by the distal radius, or indirectly by the scaphoid [3]. The proximal fragment of the capitatum is always moved with a rotation of $180^{\circ}$. These authors classify 6 types of scaphocapital fracture according to the profile radiography. In type I, the lunatum, the head of the upturned capitatum and the base of the capitatum are aligned. Types II, III and IV correspond to Fenton syndrome with carpal retrolunar dislocation. Types $\mathrm{V}$ and VI correspond to Fenton syndrome with carpal antelunar dislocation ( 3 cases in the literature). In type V, the head and the base of the capitatum are in front of the lunatum. In type $\mathrm{VI}$, only the head is in front and the base is aligned with the lunatum.

Out of 3 cases of antelunar trans scapho dislocation reported in the literature and treated orthopedically, only one case has progressed well [12]. Most authors recommend immediate surgical treatment for dislocations associated with a scaphoid fracture and for pure antelunar dislocations if the orthopedic reduction is imperfect $[9,10,13-15]$. The aim of treatment is to carry out an emergency reduction, to restore the height of the carp and to restore its spatial coherence. This helps prevent instability and osteoarthritis.
The anterior approach to the carpal antelunar fracture dislocation has recently been brought to the fore [16]. This approach offers the benefit of better control of associated intracarpal fractures.

The review of the cases published in the literature does not report avascular necrosis of the lunatum, because it often remains in its normal position under the radius awning $[6,7,12]$. No avascular scaphoid necrosis has also been reported. Fernandes, et al. [12] believe that the reason is that the main vessels of the scaphoid are in the anterolateral position and are therefore not twisted in the event of lesion by palmar hyperflexion.

In the case reported by Wodecki, et al. [2], the capitate fracture requires a posterior check. This approach allowed the reduction and osteosynthesis of the scaphoid satisfactorly. In the context of the capitatum fracture with a fracture in the cartilaginous zone as in retrolunar dislocation, osteosynthesis of the capitatum from proximal to distal with burial of the screw heads is useful. The development of miniscrews in recent years has greatly facilitated this technique [2].

After reduction, Wesely [17] recommends starting with the osteosynthesis of the capitatum to obtain a good quality carpal neocondyle. The excision of the avulsed fragment of the capitatum head formerly used is no longer required, the repositioning of the fragment with osteosynthesis having made it possible to obtain completely satisfactory results, thus justifying the principle of conservative treatment [18].

\section{Conclusion}

The possibility of carpal antelunar dislocation associated with a scaphocapital fracture should be known. As with any carpal perilunar dislocation, the preoperative radiographic assessment in traction allows the lesion assessment to be defined at best. The posterior approach helps reduce and fix the dislocation and associated fractures.

\section{Declaration of Interests}

The authors declare that they have no conflicts of interest in connection with this article.

\section{Author Contributions}

All the authors contributed to the conduct of this research work and have read and approved the final version of the manuscript.

\section{References}

1. Herzberg G, Comtet JJ, Linscheid RL, Amadio PC, Cooney 


\section{Journal of Orthopedics \& Bone Disorders}

WP, et al. (1993) Perilunate dislocations and fracture dislocations: a multicenter study. J Hand Surg 18A:768779.

2. Wodecki P, Guigui P, Masmejean E (2002) Luxation transscaphocapitale antélunaire du carpe: une nouvelle variété, une nouvelle approche. Chirurgie de la Main 21(2): 143-147.

3. VanceRM,Gelberman RH,EvansEF(1980)Scaphocapitate fractures: patterns of dislocation, mechanisms of injury, and preliminary results of treatment. J Bone Joint Surg 62A: 271-276.

4. Boisgard S, Bremont JL, Guyonnet G, Chatenet T, Levai JP (1996) Fracture scapho-capitale. A propos d'un cas, revue de la littérature. Ann Chir Main 15: 181-188.

5. Masmejean E, Cognet JM (2001) Luxation bipolaire de l'avantbras. Rev Chir Orthop (Masson, Paris) 87: 499502.

6. Aitken AP, Nalebuff AE (1960) Volar transnavicular perilunar dislocation of the carpus. J Bone Joint Surg 42A: 1051-1057.

7. Vichard P, Tropet Y, Balmat P, Brientini JM, Pem R (1991) Réflexions à propos de quatre observations de luxations antélunaires du carpe. Ann Chir Main 10(4): 331-336.

8. Ouarab M, Fnini S, Harfaoui A, Trafeh M (2000) Les luxations antélunaires du carpe. À propos de trois cas. Chir Main 19(4): 235-242.

9. Goaided B, Gargoun R, Moula T (1989) Luxation trans- scaphopérilunaire antérieure du carpe. Ann Chir Main 8: 242-245.

10. Pournaras J, Kappas A, Thessaloniki (1979) Volar perilunar dislocation. J Bone Joint Surg 61A: 768-769.

11. Fenton RL (1956) The naviculo-capitate syndrome. J Bone Joint Surg 38A: 681-684.

12. Fernandes HJA, Koberle G, Ferreira GHS, Canargo JN (1983) Volar transscaphoid perilunar dislocation. Hand 15: 276-280.

13. Roman A, Sendino M, Salomon G, Del Campo M (1994) A rare case of carpal dislocation. Ann Chir Main 13(3): 207-213.

14. Saunier J, Chamay A (1981) Volar perilunar dislocation of the wrist. Clin Orthop 157: 139-142.

15. Woodward AH, Neviaser RJ, Nisenfeld F (1997) Radial and volar perilunate transscaphoid fracture dislocation. Southern Med J 68: 926-932.

16. Masmejean E, Romano SJ, Saffar PH (1998) Palmar perilunate fracture-dislocation of the carpus. J Hand Surg 2B: 264-265.

17. Weseley MS, Barenfeld PA (1972) Transcaphoid, Tranccapitate, Transtriquetral, Perilunate fracturedislocation of the wrist. J Bone Joint Surg 54A: 10731078.

18. Haddoun AR, Rachid K, Moudene A (2004) Le syndrome de Fenton À propos d'une nouvelle observation. J Traumatol Sport 21: 58-60. 